\title{
Nanoporous membrane tube condensing heat transfer enhancement study
}

\author{
Ainan $\mathrm{Bao}^{\mathrm{a}}$, Dexin Wang ${ }^{\mathrm{a}}$, Cheng-Xian Lin ${ }^{\mathrm{b},{ }^{*}}$ \\ ${ }^{a}$ Gas Technology Institute, 1700 S Mount Prospect Rd, Des Plaines, IL 60018, United States \\ ${ }^{\mathrm{b}}$ Department of Mechanical and Materials Engineering, Florida International University, Miami, FL 33174, United \\ States
}

\begin{abstract}
A Transport Membrane Condenser (TMC), made from nanoporous membrane tube bundles, was developed to recover the water vapor and its significant amount of latent heat from boiler flue gases to improve boiler efficiency and save water. Experiments have been carried out to study the phenomena for both a nanoporous membrane tube bundle and an impermeable stainless steel tube bundle with the same characteristic dimensions. Flue gas streams with water vapor mass fraction $11.3 \%$, temperature ranges from $65^{\circ} \mathrm{C}$ to $95^{\circ} \mathrm{C}$ are used for the experimental study, which covers the typical TMC waste heat recovery application parameter range. Results show convection Nusselt numbers of the membrane tube bundle are 50 to $80 \%$ higher than that of the impermeable stainless steel tube bundle at typical condensation heat transfer conditions. The parametric study has been done by varying cooling water inlet flow rate, water inlet temperature, flue gas inlet flow rate, inlet temperature, and inlet dew point. The condensing heat transfer enhancement effect gives a good perspective for using nanoporous membrane surface to design high efficiency condensing heat exchangers to recover both water vapor and its latent heat from high moisture content low grade waste heat streams.
\end{abstract}

KEY WORD: Transport membrane condenser; Condensation; Convection heat transfer; Heat transfer enhancement

\footnotetext{
* Corresponding author, E-mail address: lincx@ fiu.edu 


\section{INTRODUCTION}

Energy efficiency of current gas-fired boiler is typically in the range of $75-85 \%$ and further improvement is mainly limited by stack loss. In gas-fired boiler application, there is about $18 \%$ in volume of water vapor in the flue gas, which usually exhausts with its substantial latent heat from the stack [1]. Figure 1 shows the theoretical relationship of boiler efficiency based on natural gas higher heating value (HHV) versus exit flue gas temperature. The $85 \%$ boiler efficiency corresponds to an exit flue gas temperature of $160{ }^{\circ} \mathrm{C}$. If the exit flue gas temperature were reduced to $50^{\circ} \mathrm{C}$ from $160{ }^{\circ} \mathrm{C}$, about $7 \%$ additional boiler efficiency could be gained. From 1970 s, condensing devices have been developed for boiler applications to reduce stack loss. As a result, it is of great significance for energy conservation to study condensing device heat transfer [2].

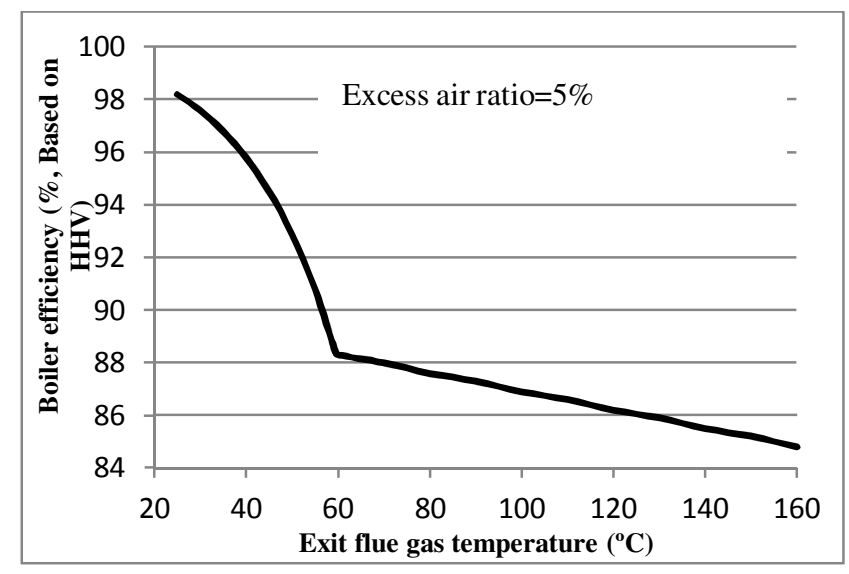

Figure 1. Relationship of gas-fired boiler efficiency versus exit flue gas temperature

In recent years, Gas Technology Institute (GTI) has developed a new technology based on a nanoporous ceramic separation membrane to extract a portion of the water vapor and its latent heat from flue gases and return the recovered water and heat to the boiler steam cycle [3, 4]. Water vapor condenses inside the membrane pores and passes to the permeate side which is in direct contact with a low-temperature water stream. Contaminants of flue gases such as $\mathrm{CO}_{2}, \mathrm{O}_{2}, \mathrm{NO}_{\mathrm{x}}$, and $\mathrm{SO}_{2}$ are inhibited from passing through the membrane by the membrane high selectivity [5, 6, and 7]. The recovered water is of high quality, therefore can be used as supplemental makeup water for almost all industrial processes. Figure 2 shows the photomicrograph of ceramic porous layer coated on the porous membrane tube surface. It consists of a top layer with a pore size of 60 to $80 \AA$ (about 2 to $4 \mu \mathrm{m}$ thick), a 500 A pore size intermediate layer (typically 20 to $50 \mu \mathrm{m}$ thick), and a $0.4 \mu \mathrm{m}$ pore size substrate (about $1 \mathrm{~mm}$ thick). This structure is used for both polymeric and ceramic nanoporous separation membranes to achieve high separation ratio with minimal resistance to flux of the permeating species.

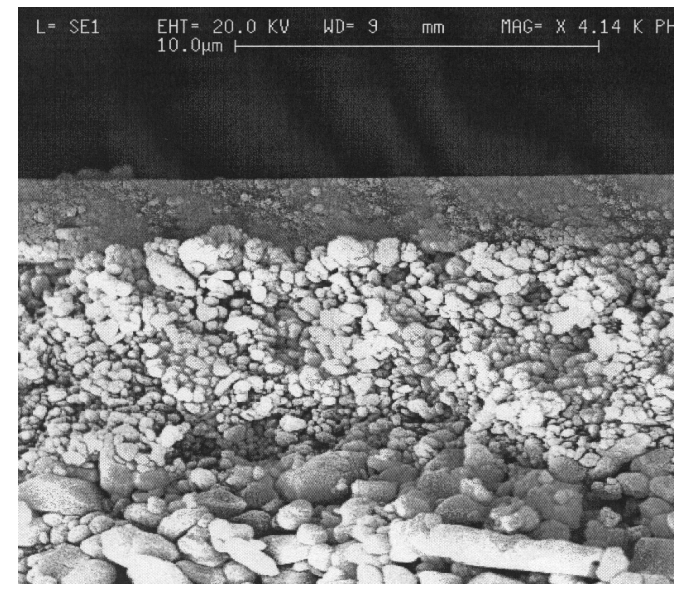

Figure 2. Photomicrograph of a porous ceramic membrane tube cross-section 
Single-phase convective heat transfer over a bare tube bundle has been investigated long time ago. Zukauskas $[8,9]$ developed correlation equations for predicting mean convection Nusselt number between a horizontal tube bundle and a fluid flowing over the bundle exterior surface. The correlation equation is of the form

$$
\mathrm{Nu}_{\text {conv }}=\mathrm{CRe}^{\mathrm{m}} \operatorname{Pr}^{0.36}\left(\operatorname{Pr} / \operatorname{Pr}_{\mathrm{w}}\right)^{0.25}
$$

Where $\mathrm{Nu}_{\text {conv }}=\mathrm{hd}_{\mathrm{o}} / \lambda$ is convection Nusselt number, $\mathrm{Re}=\mathrm{ud}_{\mathrm{o}} / \nu$ is Reynolds number, and $\operatorname{Pr}=v / \mathrm{a}$ is Prandtl number. For the investigation of heat transfer over a tube bundle, Reynolds number is based on the tube outer diameter $d_{o}$ as the characteristic length and the velocity $u$ at the minimum flow area as the characteristic velocity.

Flow and heat transfer with condensation of the tube bundle in moistened gas mixture was also studied in the past, and recent studies include Che et al. [10, 11], and Osakabe [12, 13]. Che et al. have investigated the convection-condensation heat and mass transfer through a 20-mm-outer-diamater in-line impermeable carbon steel tube bundle, within the range of flue gas Reynolds number of 3900-7300. Osakabe measured the condensation heat transfer on $10.5 \mathrm{~mm}$ and $4 \mathrm{~mm}$ outer diameter staggered stainless steel tube bundles in actual flue gas, and developed a prediction method to calculate the convection-condensation heat transfer Nusselt number. For impermeable tube bundles, experimental results show convection-condensation heat transfer coefficients are 1-3.5 times higher than those of the forced convection without condensation. And experiments also show tube bundles exterior surface are partially or totally wetted by condensate, and water film thickness and its heat resistance affect heat transfer and condensation.

To enhance the convection-condensation heat transfer between bundles and a fluid, some approaches by modifying the heat transfer surface are used, such as porous medium coated surface. Renken et al. [14] have presented experimental results for force convection pure steam condensation heat transfer on an impermeable porous-layer coated surface. Results show the porous coating produces a considerable heat transfer enhancement ( $250 \%$ higher) compared with noncoated surface. To our knowledge, heat transfer between permeable tube bundles and actual flue gases with condensation process has not been investigated.

In this paper, a permeable nanoporous membrane tube bundle was built to recover both water vapor and its significant amount of latent heat from flue gases. Experiments were conducted to compare the convectioncondensation heat transfer performance of a porous membrane tube bundle with an impermeable stainless steel tube bundle. Based on the experimental data, convection Nusselt numbers in flue gas side and condensation rates for both bundles are compared. Parametric study was also carried out by varying cooling water flow rate, cooling water inlet temperature, flue gas inlet flow rate, flue gas inlet temperature, and flue gas inlet dew point.

\section{NOMENCLATURE}

$\begin{array}{ll}\mathrm{A} & \text { bundle surface area }\left(\mathrm{m}^{2}\right) \\ \mathrm{A}_{\mathrm{c}} & \text { cooling water flow cross section area }\left(\mathrm{m}^{2}\right) \\ \mathrm{B}_{\mathrm{l}} & \text { longitudinal pitch of the tubes }(\mathrm{m}) \\ \mathrm{B}_{\mathrm{t}} & \text { transverse pitch of the tubes }(\mathrm{m}) \\ \mathrm{C}_{\mathrm{p}} & \text { specific heat }(\mathrm{J} / \mathrm{kg}-\mathrm{K}) \\ d & \text { tube diameter }(\mathrm{m}) \\ \mathrm{g}_{\mathrm{m}} & \text { mass transfer coefficient }\left(\mathrm{kg} / \mathrm{m}^{2} \mathrm{~s}\right) \\ \mathrm{h} & \text { heat transfer coefficient }\left(\mathrm{W} / \mathrm{m}^{2} \mathrm{~s}\right) \\ \mathrm{L} & \text { tube length }(\mathrm{m}) \\ \mathrm{L}_{\mathrm{w}} & \text { latent heat of condensation }(\mathrm{kJ} / \mathrm{kg}) \\ \mathrm{MTD} & \text { Mean Temperature Difference } \\ \mathrm{m} & \text { mass flow rate }(\mathrm{kg} / \mathrm{s} \text { or } \mathrm{kg} / \mathrm{min}) \\ \mathrm{n} & \text { total tube number of a bundle } \\ \mathrm{Nu} & \text { Nusselt number hd } / \lambda \\ \mathrm{P} & \text { pressure }(\text { Pa }) \\ \mathrm{Pr} & \text { Prandtl number } \\ \mathrm{Q} & \text { water volumetric flow rate }\left(\mathrm{m}^{3} / \mathrm{s}\right) \\ \mathrm{R} & \text { heat resistance }\left(\mathrm{m}{ }^{2} \mathrm{~s} / \mathrm{W}\right) \\ \mathrm{Re} & \text { Reynolds number ud } / \mathrm{v} \\ \mathrm{T} & \text { temperature }\left({ }^{\circ} \mathrm{C}\right)\end{array}$


W mass fraction

F heat flux $\left(\mathrm{W} / \mathrm{m}^{2}\right)$

$\gamma \quad$ porosity

$\lambda$ thermal conductivity $(\mathrm{W} / \mathrm{mK})$

$v \quad$ kinematic viscosity $\left(\mathrm{m}^{2} / \mathrm{s}\right)$

$\Delta \mathrm{T}_{\mathrm{m}} \quad \mathrm{MTD}$, mean temperature difference $\left({ }^{\circ} \mathrm{C}\right)$

Subscripts

$\begin{array}{ll}\text { conv } & \text { convection } \\ \text { cond } & \text { condensation } \\ \text { i } & \text { inlet or inner } \\ \text { int } & \text { interface } \\ \text { FG } & \text { flue gas } \\ \text { o } & \text { outlet or outer } \\ \text { v } & \text { vapor } \\ \text { w } & \text { water }\end{array}$

\section{EXPERIMENTAL INVESTIGATION}

Porous membrane tube bundle and impermeable stainless steel tube bundle

A nanoporous ceramic membrane tube bundle and an impermeable stainless steel tube bundle with the same characteristic dimensions were built to study their heat transfer and condensation phenomena. Both bundles have 78 tubes in 12 rows with a staggered arrangement. The longitudinal pitch $B_{1}$ is $13.6 \mathrm{~mm}$, the transverse pitch $B_{t}$ is 8.8 $\mathrm{mm}$, and the tube length $L$ is $432 \mathrm{~mm}$, for both bundles. Figure 3 shows the staggered arrangement in the tube bundle. For the porous membrane tubes, the porosity was estimated at $30 \%$. Dimensions for the porous membrane tube bundle and the impermeable stainless steel tube bundle are listed in Table 1. The impermeable tubes are made from type 304 stainless steel.

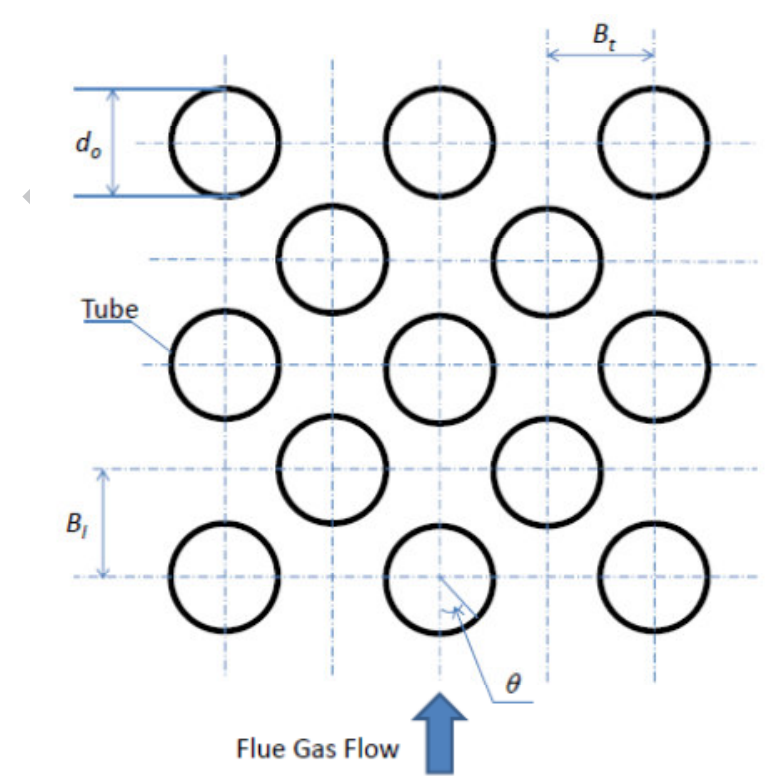

Figure 3. Staggered arrangement of the tube bundle 
Table 1: Dimensions of the impermeable tube bundle and the porous membrane tube bundle

\begin{tabular}{|l|l|l|}
\hline & Stainless-steel tube & Porous membrane tube \\
\hline Material & Stainless-steel 304 & Alumina (porosity 30\%) \\
\hline Outer diameter $\left(d_{o}, \mathrm{~mm}\right)$ & 6.3 & 5.5 \\
\hline Inner diameter $\left(d_{i}, \mathrm{~mm}\right)$ & 4.7 & 3.5 \\
\hline Wall thickness $(\mathrm{mm})$ & 0.8 & 1.0 \\
\hline Length $(\mathrm{L}, \mathrm{mm})$ & 432 & 432 \\
\hline $\begin{array}{l}\text { Cross section for flue flow }(\mathrm{mm} \times \\
\text { mm) }\end{array}$ & $430 \times 90$ & $430 \times 90$ \\
\hline Longitudinal pitch $\left(B_{l}, \mathrm{~mm}\right)$ & 13.6 & 13.6 \\
\hline Transverse pitch $\left(B_{t}, \mathrm{~mm}\right)$ & 8.8 & 8.8 \\
\hline Number of tubes $(\mathrm{n})$ & 78 & 78 \\
\hline
\end{tabular}

\section{Test Rig}

Figure 4 is the schematic of the experimental apparatus. As shown in Fig. 4, flue gas from a natural gas combustor flows into the duct, where it is cooled to the desired temperature by the flue gas cooling section. And then the flue gas flows upwards through the test section where test bundle installed. Cooling water flows into the bundle in a cross-flow arrangement with the flue gas. For the impermeable stainless steel tube bundle, its condensate drains out from the bottom drain port of the duct. For the porous membrane tube bundle, vapor mass transfer is driven by water vapor partial pressure difference across the membrane wall, and assisted by a vacuum generator which can create a vacuum at 3 to 12 inch mercury below atmosphere in the permeate side. Cooling water inlet temperature can be adjusted to desired temperature by an electrical water heating system. An observation window was installed into the test section to observe the condensation phenomena on tube bundle surface. The flow rates for natural gas, combustion air, and cooling water are measured by different flow meters. Flue gas temperatures and water temperatures are measured by thermocouples. Flue gas inlet and outlet dew points are measured by hygrometers. All experimental data are collected by a data acquisition system for post-processing.

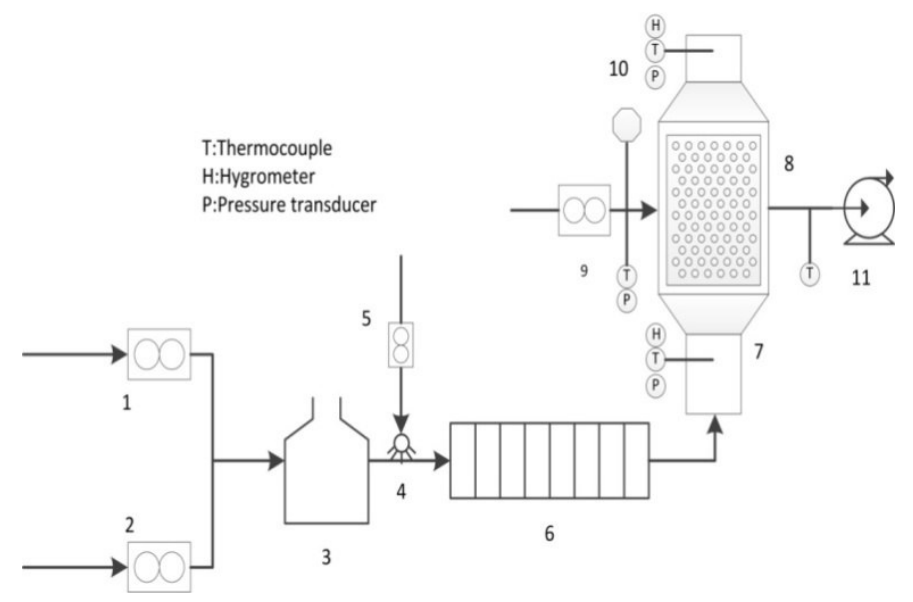

Figure 4. Schematic of experimental apparatus: 1 Natural gas flow meter; 2 Compressed air flow meter; 3 Natural gas combustor; 4 Water injection nozzle; 5 Water flow meter; 6 Flue gas cooling section; 7 Test duct; 8 Porous membrane tube bundle or stainless steel tube bundle; 9 Cooling water flow meter; 10 Vacuum generator; 11 Cooling water pump 


\section{Measurement and data processing}

The mean convection Nusselt numbers in flue gas side and the water vapor condensation rates are two main parameters used to compare the heat transfer performance between the porous membrane tube bundle and the impermeable stainless steel tube bundle.

Figure 5 shows temperature and vapor partial pressure distributions around a porous membrane tube and an impermeable stainless steel tube $[10,15]$. When there is a non-condensable gas presented in a gas mixture, a noncondensable gas boundary layer will be attached to the condensate film and the vapor must diffuse through it to arrive at the liquid-vapor interface for condensing. Water vapor concentration difference between the bulk $W_{F G}$ and the interface $W_{i n t}$ is the driving force for mass transfer and the temperature difference between the bulk $T_{F G}$ and the interface $T_{i n t}$ is the driving force for convection heat transfer. At an equilibrium condition, the liquid-vapor interface vapor partial pressure $P_{i n t, v}$ is equal to the vapor saturation pressure at the interface temperature $T_{i n t}$. For the porous membrane tube, interface temperature $T_{\text {int }}$ and vapor concentration $W_{\text {int }}$ are equal to the tube outer surface temperature $T_{o}$ and vapor concentration $W_{o}$ respectively, as no condensate accumulates on the tube surface. In this study, for the impermeable tube bundle, the heat resistance in flue side includes the additional condensate layer heat resistance.

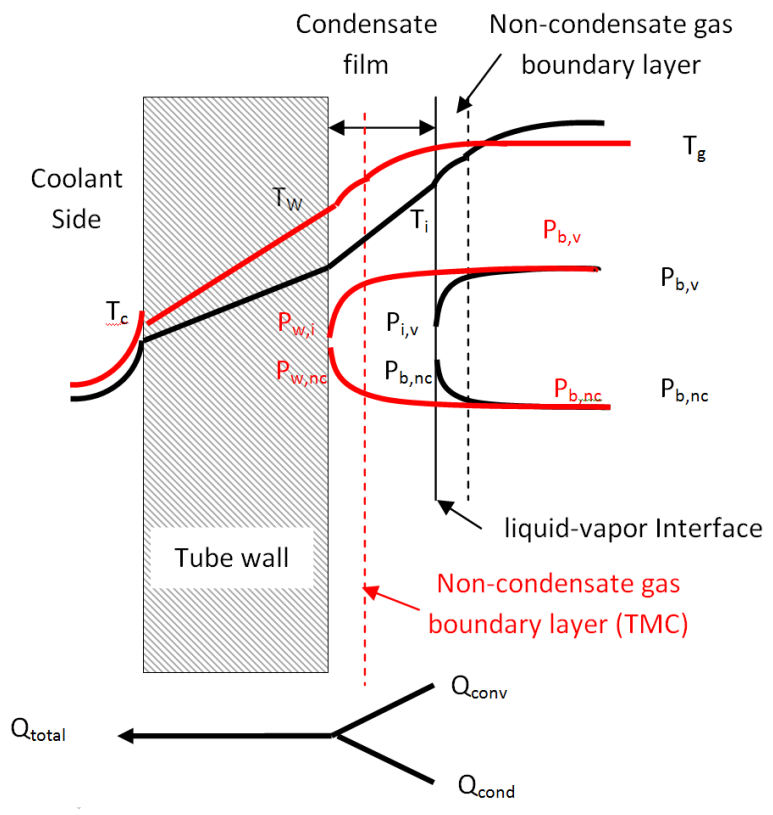

Figure 5. Temperature and vapor pressure distributions across a tube cross section

As shown in Fig. 5, for a single tube with the length $L$, inner diameter $d_{i}$, and outer diameter $d_{o}$, the heat resistance by conduction through the tube wall is:

$$
R=\ln \left(d_{o} / d_{i}\right) /(2 \pi \lambda L)
$$

where $\lambda$ is the thermal conductivity of tube material. The porous membrane tubes are sintered by fine alumina $\left(\mathrm{Al}_{2} \mathrm{O}_{3}\right)$ particles, with average porosity $\gamma=30 \%$. The effective thermal conductivity for porous membrane tubes is given by:

$$
\lambda_{\text {eff }}=(1-\gamma) \lambda_{\text {alumina }}+\gamma \lambda_{\mathrm{w}}
$$

Here, $\lambda_{\text {alumina }}$ and $\lambda_{\mathrm{w}}$ are thermal conductivities for alumina and water, and the effective conductivity $\lambda_{\text {eff }}$ is $24.7 \mathrm{~W} / \mathrm{m}-\mathrm{K}$. The thermal conductivity for type 304 stainless steel is $15.2 \mathrm{~W} / \mathrm{m}-\mathrm{K}$.

At the water side of the bundles, the maximum water flow characteristic velocities for the impermeable stainless steel tube bundle and the porous membrane tube bundle are $0.0466 \mathrm{~m} / \mathrm{s}$ and $0.0866 \mathrm{~m} / \mathrm{s}$, respectively. Therefore the maximum Reynolds numbers of water side are 217 for the impermeable tube bundle and 301 for the porous 
membrane tube bundle. As a result, the inside-tube water flows are fully developed laminar flows, and the convection heat transfer coefficient in water side is obtained by [16, 17]:

$$
N u_{w}=0.023 R e_{w}^{0.8} \operatorname{Pr}_{w}^{0.4}
$$

where $R e_{w}=Q d_{i} / v A_{c}, Q$ is the cooling water volumetric flow rate $\left(\mathrm{m}^{3} / \mathrm{s}\right), d_{i}$ is the tube inner diameter, $A_{c}$ is cooling water flow cross-sectional area, and $v$ is the water kinematic viscosity. Heat transfer coefficient in water side is calculated from $h_{w}=N u_{w} \lambda_{w} / d_{i}$.

Extend a single tube heat transfer analysis to the bundles, and the mean temperatures are calculated by:

$$
\begin{aligned}
\overline{T_{F G}}-T_{o} & =\Phi_{s} / h_{s} \pi d_{o} L \\
T_{o}-T_{i} & =\left(\Phi_{s}+\Phi_{L}\right) / 2 \pi \lambda L * \ln \left(d_{o} / d_{i}\right) \\
T_{i}-\overline{T_{W}} & =\left(\Phi_{s}+\Phi_{L}\right) / h_{W} \pi d_{i} L
\end{aligned}
$$

Here $\overline{\mathrm{T}_{\mathrm{FG}}}$ is the mean temperature in flue gas side, $\overline{\mathrm{T}_{\mathrm{W}}}$ is the mean temperature in water side, and $T_{o}$ and $T_{i}$ are outer and inner surface temperatures of the tube wall.

The sensible heat transfer and latent heat transfer quantities through the bundles are:

$$
\begin{aligned}
& \Phi_{s}=\left(m_{F G}-m_{\text {cond }}\right) C_{p, F G}\left(T_{F G, i}-T_{F G, o}\right)-m_{\text {cond }} C_{p, v}\left(T_{F G, i}-T_{o}\right) \\
\Phi_{L}= & L_{w}\left(m_{F G} W_{F G, i}-\left(m_{F G}-m_{\text {cond }}\right) W_{F G, o}\right)
\end{aligned}
$$

where $m_{F G}$ is the flue gas mass flow rate, $C_{p, F G}$ is the flue gas specific heat, $C_{p, v}$ is the vapor specific heat, $L_{w}$ is the latent heat, $m_{c o n d}$ is the condensation rate, $T_{i n t}$ is the mean tube outer surface temperature, and $T_{F G, i}, T_{F G, o}$, $W_{F G, i}, W_{F G, o}$ are the flue gas inlet and outlet temperatures and vapor mass concentrations, respectively. The condensation rate is calculated by:

$$
m_{\text {cond }}=\left(W_{F G, i}-W_{F G, o}\right) /\left(1-W_{F G, o}\right)
$$

Combining Eqs. 5, 6, and 7, convection heat transfer coefficients in flue gas side for both tube bundles can be determined by the followings:

$$
h_{s}=\Phi_{s} /\left(n \pi d_{o} L\left(\Delta T_{m}-\left(\Phi_{s}+\Phi_{L}\right) / 2 n \pi \lambda L * \ln \left(d_{o} / d_{i}\right)-\left(\Phi_{s}+\Phi_{L}\right) /\left(n h_{W} \pi d_{i} L\right)\right)\right.
$$

where $n$ is the total number of tubes in the bundles. $\Delta T_{m}$ is the heat exchanger Mean Temperature Difference (MTD), and $\Delta \mathrm{T}_{\mathrm{m}}=\overline{\mathrm{T}_{\mathrm{FG}}}-\overline{\mathrm{T}_{\mathrm{W}}}$. Convection Nusselt number in flue gas side is determined by $N u_{\text {conv }}=h_{s} d_{d} \lambda_{F G}$.

Physical properties, such as density, viscosity, latent heat, and heat conductivity, are from the database [18]. The Kline and McClintock method [19] has been used to calculate the uncertainties of experimental results. The ranges and uncertainties of the measured parameters are listed in Table 2. The uncertainty of flue gas Reynolds number is $3.0 \%$, the uncertainty of the condensation rate is $6.5 \%$, and the uncertainty of convection Nusselt number is $8.0 \%$. 
Table 2. Experimental uncertainties

\begin{tabular}{ccc}
\hline Parameters & Uncertainty & Range \\
\hline Water flow rate & $0.02 \mathrm{~kg} / \mathrm{min}$ & $1.71-8.35 \mathrm{~kg} / \mathrm{min}$ \\
Water inlet & $0.1^{\circ} \mathrm{C}$ & $19.1-44.6^{\circ} \mathrm{C}$ \\
Water outlet & $0.1^{\circ} \mathrm{C}$ & $33.5-56.1^{\circ} \mathrm{C}$ \\
Flue gas flow rate & $0.03 \mathrm{~kg} / \mathrm{min}$ & $2.36-2.80 \mathrm{~kg} / \mathrm{min}$ \\
Flue gas inlet & $0.1^{\circ} \mathrm{C}$ & $64.7-93.5^{\circ} \mathrm{C}$ \\
Flue gas outlet & $0.1^{\circ} \mathrm{C}$ & $45.2-57.3^{\circ} \mathrm{C}$ \\
Flue gas inlet vapor & $0.2 \%$ & $11.3 \%$ \\
Flue gas outlet vapor & $0.2 \%$ & $5.3-11.3 \%$ \\
\hline
\end{tabular}

\section{RESULTS AND DISCUSSION}

Experiments have been carried out to compare the heat and mass transfer performance between the porous membrane tube bundle and the impermeable stainless steel tube bundle. For the porous membrane tube bundle, flue gas inlet velocity is $0.50 \mathrm{~m} / \mathrm{s}$, inlet temperature is from $65^{\circ} \mathrm{C}$ to $95^{\circ} \mathrm{C}$, and vapor mass fraction is $11.3 \%$. These inlet conditions are the typical flue gas stack conditions for industrial applications. Reynolds number for the porous membrane tube bundle is 260 . For impermeable stainless steel bundle, flue gas inlet velocity is $0.44 \mathrm{~m} / \mathrm{s}$ and Reynolds number is 280 .

The relationship of convection Nusselt number in flue gas side versus Mean Temperature Difference (MTD) is shown in Fig. 6. The relationship of the mass transfer coefficient versus MTD is shown in Fig. 7, and the mass transfer coefficient $\mathrm{g}_{\mathrm{m}}$ representing condensation rates for both bundles is:

$$
\mathrm{g}_{\mathrm{m}}=\mathrm{m}_{\text {cond }} / A
$$

where $A$ is the bundle surface area, and $m_{\text {cond }}$ is the condensation rate.

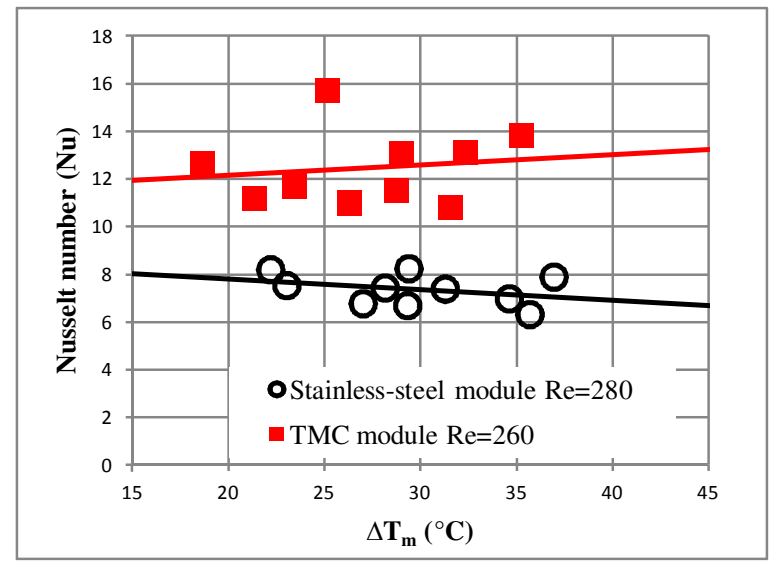

Figure 6.MTD effect on convection Nusselt number in flue gas side

For the impermeable (solid) stainless steel tube bundle, when MTD ranges from $20^{\circ} \mathrm{C}$ to $25^{\circ} \mathrm{C}$, convection Nusselt number is about 8.0 and the condensation rate is very low, as shown in Figs. 6 and 7. For these experimental conditions, the heat transfer through the bundle can be considered as forced convection only, and the Zukauskas' correlation equation predicts Nusselt number as 8.7, from Eq. (1). Experimental convection Nusselt number is consistent with the Zukauskas' correlation prediction. When MTD increases, the mass transfer coefficient increases and more condensate is accumulated on the impermeable tube surface. The thicker condensate film increases heat resistance and reduces convection Nusselt number, as shown in Fig. 6. For the porous membrane tube bundle, at the same MTD, convection Nusselt numbers are $50 \%$ to $80 \%$ higher than those of the impermeable stainless steel tube 
bundle, as shown in Fig. 6. The mass transfer coefficients for the porous membrane tube bundle are $60 \%$ to $80 \%$ higher than those of the impermeable stainless steel tube bundle at the same MTD.

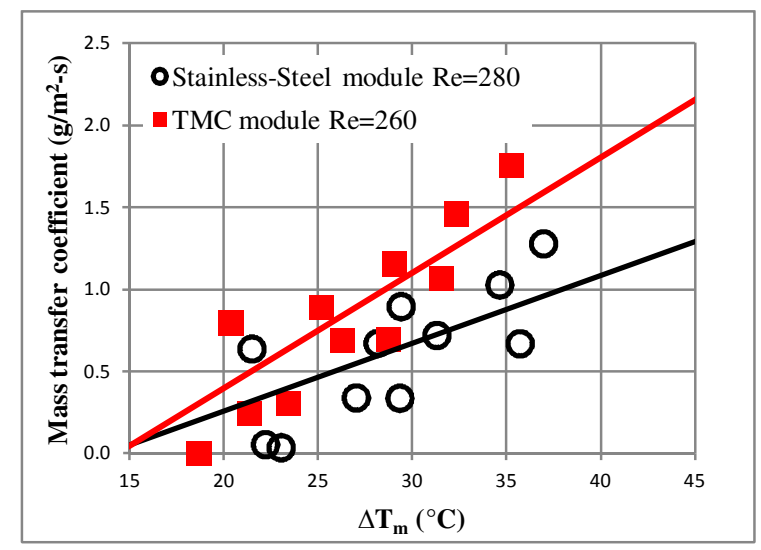

Figure 7. MTD effect on condensation rate

The primary reason for the convective heat transfer enhancement on the flue gas side for the porous membrane tubes is due to the removal of the condensate from flue gas side to the water side, which reducing the convective thermal resistance on the outer surface of the tubes. The reduction of water vapor mass fraction increases flue gas thermal conductivity, which also contribute the convective heat transfer enhancement in flue gas side for the porous membrane tube bundle. The removal of the condensate from the outer surface of the porous tubes into the water side will also enhance the condensation heat transfer as much thinner liquid layer will be formed as compared to the surfaces of the solid tubes. Combined with the convective heat transfer increases in the flue gas, the interface temperature $T_{i n t}$ between the gaseous phase and liquid phase is lowered, producing higher condensation heat transfer. Furthermore, for the nanoporous membrane tubes, the condensation rates are higher than the regular tubes because of the effects of capillary condensation phenomena. Based on the pore capillary condensation mechanism, Kelvin equation [20], pore condensation can occur when membrane surface relative humidity is below $100 \%$, when the membrane pore size is in the nanometer scale. The onset of the capillary condensation is considered to increase the condensation rates, therefore the overall condensation heat transfer.

Figure 8 shows the relationship of overall Nusselt numbers versus MTD for both the porous membrane tube bundle and the impermeable stainless steel tube bundle. Overall Nusselt numbers represent a combined effect of convection and condensation heat transfer. The results show sensible heat and latent heat transfer are enhanced by porous membrane tubes, and overall Nusselt numbers increase 50\% compared with the impermeable tube bundle. For the impermeable tube bundle, the convection-condensation Nusselt numbers are 0.5-2 times higher than those of the forced convection only, which are consistent with results from Che and Osakabe [10, 12]. For the porous membrane tube bundle, its convection-condensation Nusselt numbers are 0.5-4 times higher than those with convection only conditions.

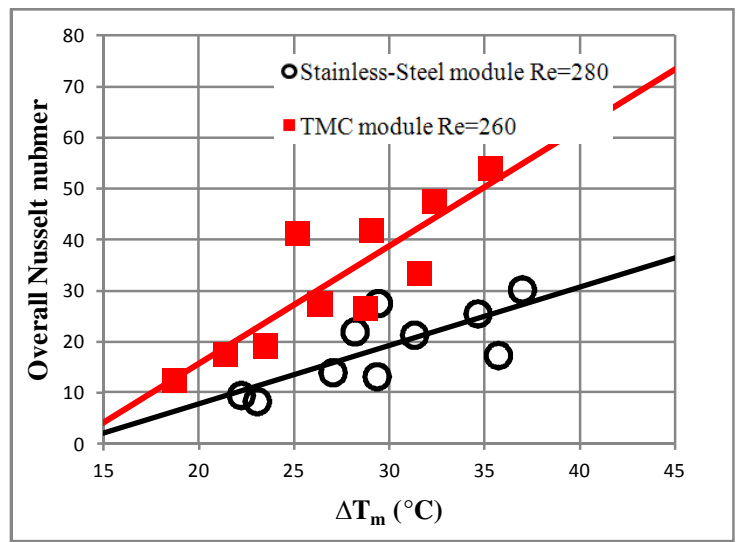

Figure 8. MTD effect on overall Nusselt number 
Parametric study of the porous membrane tube bundle is conducted by varying cooling water inlet temperature and flow rate, flue gas inlet temperature, dew point and flow rate, and vacuum at the cooling water side. The results are shown in Figs. 9-13. The water side vacuums have been varied from 3 inch to 12 inch mercury below atmosphere, and results show the vacuum has little effect on heat transfer and mass transfer. As shown in Fig. 9, when cooling water inlet temperature decreases, the condensation rate and condensation heat transfer flux are boosted, and overall heat transfer flux increases. It can be observed from Fig. 10 that when water flow rate increases, the overall heat transfer flux increases. Flue gas inlet temperature effect on overall heat transfer flux is minor, when the flue gas inlet temperature is higher than $80^{\circ} \mathrm{C}$, as shown in Fig. 11. Figures 12 and 13 show that overall heat transfer flux increases, when the flue gas inlet dew point or inlet flow rate increases. The parametric study shows this heat transfer enhancement method works well in a wide parameter range for typical flue gas conditions.

The convection-condensation heat transfer performance for a porous membrane tube bundle has been investigated in this study. The overall heat transfer enhancement gives a good perspective for using nanoporous membrane tubes to design high efficiency condensing heat exchangers to recover both water vapor and its latent heat from high moisture content low grade waste heat streams. Based on experimental results and numerical results [15], the following correlation is developed for convective heat transfer of the porous membrane tube bundles:

$$
N u_{w}=0.5 \operatorname{Re}^{0.6} \operatorname{Pr}^{0.36}\left(\operatorname{Pr} / \operatorname{Pr}_{w}\right)^{0.25}(\operatorname{Re}<1200)
$$

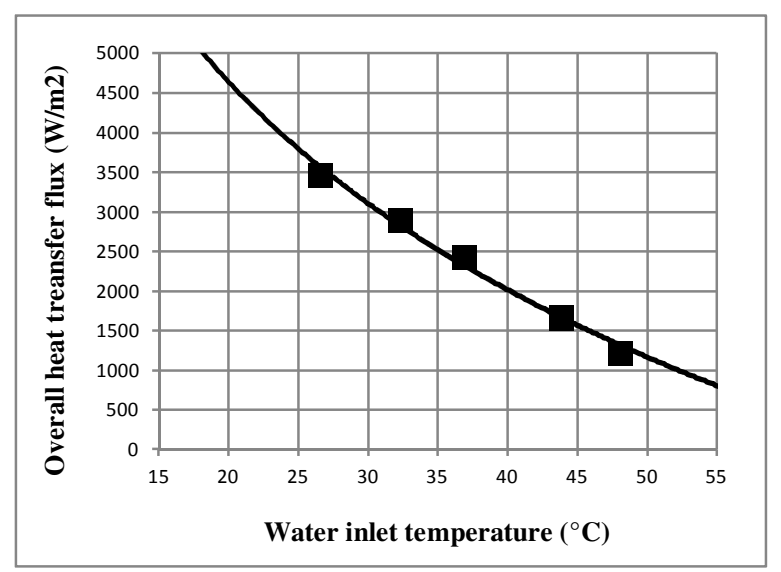

Figure 9. Water inlet temperature effect on overall heat transfer (water flow rate@ $1.25 \mathrm{~kg} / \mathrm{min}$ )

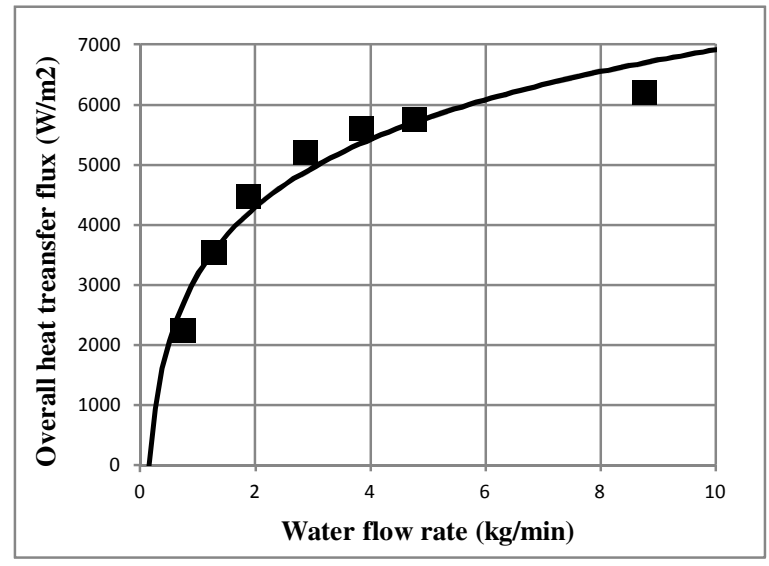

Figure 10. Water inlet flow rate effect on overall heat transfer (water inlet temperature @ $25^{\circ} \mathrm{C}$ ) 


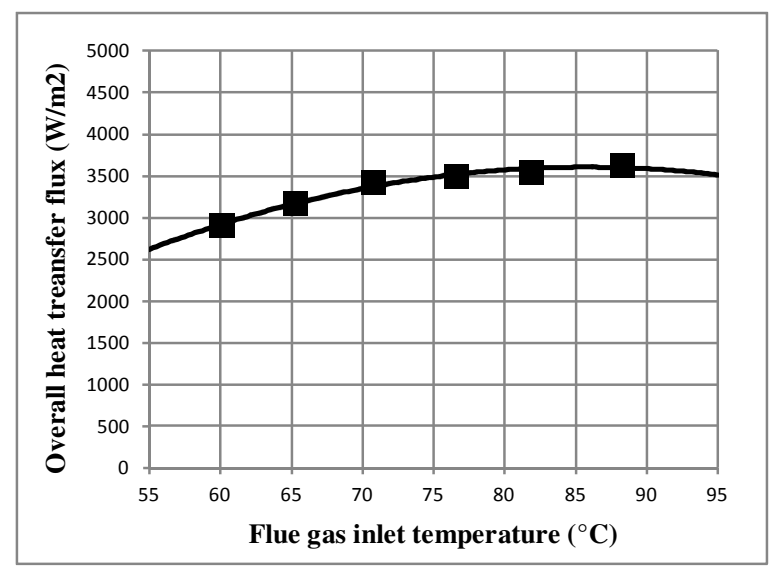

Figure 11. Flue gas inlet temperature effect on overall heat transfer

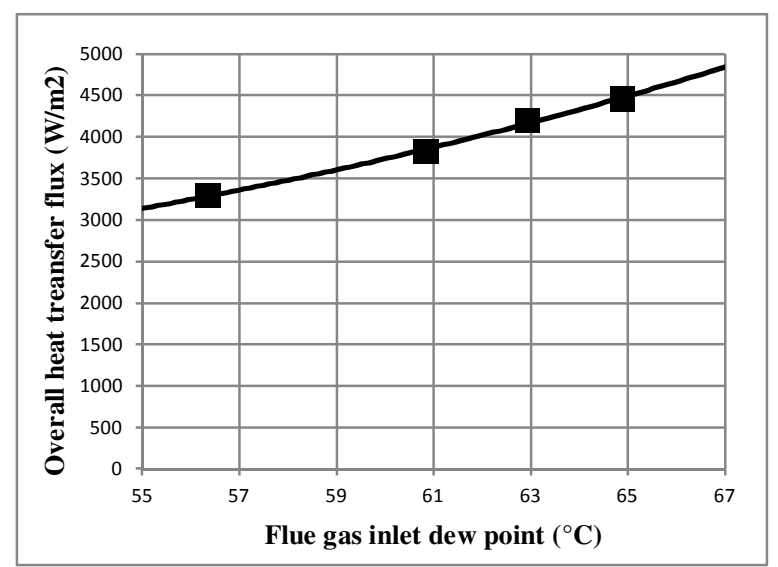

Figure 12. Flue gas inlet dew point effect on overall heat transfer

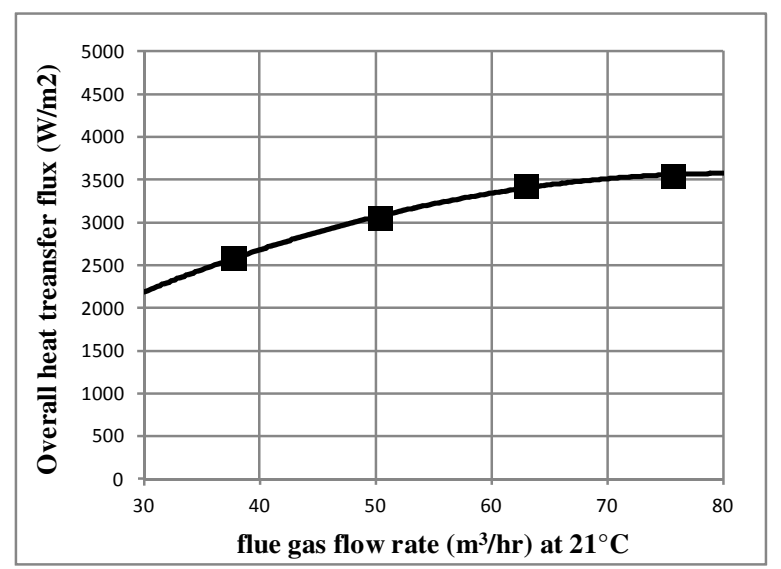

Figure 13. Flue gas flow rate effect on overall heat transfer

\section{CONCLUSIONS}

A nanoporous membrane tube bundle was built to study its convection-condensation heat transfer behavior when it was used to recover both water vapor and latent heat from water vapor laden flue gases. 
Experimental results show that condensation and convection through the porous membrane bundle are both significantly enhanced over an impermeable tube bundle, because of the membrane capillary condensation mechanism and the continuous evacuation of the condensate water through the membrane pores. Convection Nusselt numbers in flue gas side for the porous membrane tube bundle are 50\% to $80 \%$ higher than those for the impermeable stainless steel tube bundle. The condensation rates for the porous membrane tube bundle also increase $60 \%$ to $80 \%$.

Within the examined parameter ranges, it was shown that overall heat transfer flux can be increased by increasing cooling water flow rate, flue gas inlet temperature, flue gas inlet dew point, and flue gas flow rate.

\section{ACKNOWLEDGMENTS}

The authors would like to acknowledge the financial support from U.S. Department of Energy Industrial Technologies Program under award number DE-EE0003477, and National Energy Technology Laboratory under award number DE-NT0005350. 


\section{REFERENCES}

[1] J. Boyen, Thermal Energy Recovery, John Wiley \& Sons, 1980.

[2] BCS, Inc. Waste Heat Recovery-Technology and Opportunities in US Industry, Department of Energy Final Project Report, 2008

[3] D.Wang, Advanced Energy and Water Recovery Technology from Low Grade Waste Heat, Department of Energy Project Final Report DE-EE0003477, 2011

[4] D.Wang, A.Bao, W.Kunc, and W.Liss, Coal Power Plant Flue Gas Waste Heat and Water Recovery, Applied Energy 91(1) (2011) 341-348

[5] H.Strathman, B.Bauer, J. Kerres , Polymer Membranes with Selective Gas and Vapor Permeation Properties, Makromo. Chem 33 (1990) 161-178

[6] W.Koros, "Gas Sepearation Membranes: Needs for Combined Materials Science and Processing Approaches", Macromol. Symp. 188 (2002) 13-22

[7] H.Cong, M.Radosz, B.Towler, Y.Shen, Polymer-inorganic Nanocomposite Membranes for Gas Separation, Separation Purification Tech. 55 (2007) 281-291

[8] A.Zukauskas, Heat transfer from Tubes in Cross Flow ,Adv. Heat Transfer, Academic 8 (1972) 93-106

[9] A.Zukauskas, Convective Heat Transfer in Heat Exchange, Nauka, Moscow, 1982

[10] D.F. Che, Y.D.Da, Z.N.Zhuang, Heat and Mass Transfer Characteristics of Simulated High Moisture Flue Gases, Heat Mass Transfer 41 (2005) 250-256

[11] Y.B. Liang, D.F.Che, Y.B.Kang, Effect of vapor condensation on Force Convection Heat Transfer of Moistened Gas, Heat Mass Transfer 43 (2007) 677-686

[12] M.Osakabe, S. Horiki, Y. Hanaki, Prediction and Performance of Compact Heat Exchanger with Small Diameter Tubes for Latent Heat Recovery, J. Environ. and Eng. 4 (2009) 36-46

[13] M.Osakabe, T.Itoh, and M. Ohamasa, Condensation heat transfer on tubes in actual flue gas (Experiment using flue gas at different air ratios ), Trans, of JSME 64-626 (1998) 3378-3383

[14] K.J.Renken, M.R.Raich, Forced Convection Steam Condensation Experiments within Thin Porous Coatings, Int. J. of Heat and Mass Transfer 39 (2001) 2937-2945

[15] C.Lin, D, Wang, A.Bao, Numerical Modeling and Simulation of Condensation Heat transfer of a Flue Gas in a Bundle of Transport Membrane Tubes, Int. J. of Heat and Mass Transfer 60 (2013) 41-50

[16] E.Naess, Experimental Investigation of Heat transfer and Pressure Drop in Serrated-fin Tube Bundles with Staggered Tube Layouts, Applied Thermal Eng. 30 (2010) 1531-1537

[17] F. Kreith, M.S.Bohn, Principles of Heat Transfer, Happer \& Row, 1986

[18] http://webbook.nist.gov/chemistry/

[19] S.J.Kline, F.A. McClintock, Describing Uncertainties in Single-Sample Experiments, Mech. Eng., 1953

[20] S.J. Gregg, K.S.W.Sing, Adsorption, Surface Area and Porosity, Academic Press, 1982 
Flue gas condensation in nanoporous tube bundles was investigated experimentally Naoporous tubes enhanced convection heat transfer by $50-80 \%$

Condensation rate could be improved by increasing flue gas inlet dew point 